\title{
Impact of heavy metals on human toxicity using LCA: the case study of Walloon corn
}

Saïcha Gerbinet

saicha.gerbinet@ulg.ac.be

Products, Environment, and Processes (PEPs)

Chemical Engineering

Université de Liège

www.chimapp.ulg.ac.be

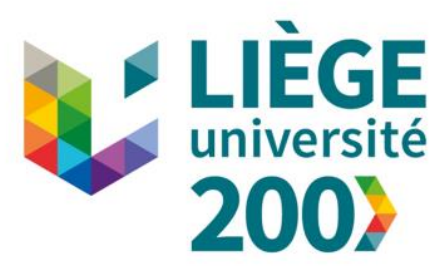




\section{Introduction}

- Context

- Study of biobased products

- From cereals

- Detailed analysis of the results

-Why toxicity so high? 


\section{Corn production in Wallonia}

- Thanks to F. Van Stappen (CRA-W)

Functional unit: 1 ha

- System boundaries:

- Inputs production (mineral fertilizers, seed, machinery, phytosanitary

- Agricultural phase:

product, etc.) + transport

- Soil preparation, sowing, fertilization, plant protection, harvest

- Including field emissions: « mostly used » models 
- Using USEtox as recommended by ILCD

- Human toxicity, cancer effect

- Human toxicity, non-cancer effect

\section{USEtox ${ }^{\circledR}$}

The characterization factors (CF) $=$ effects $\left[\right.$ cases $/ \mathrm{kg}$ intake ${ }^{*}$ intake fraction $[\mathrm{kg}$ intake $/ \mathrm{kg}$ emitted 


\section{Human toxicity, Cancer effect}

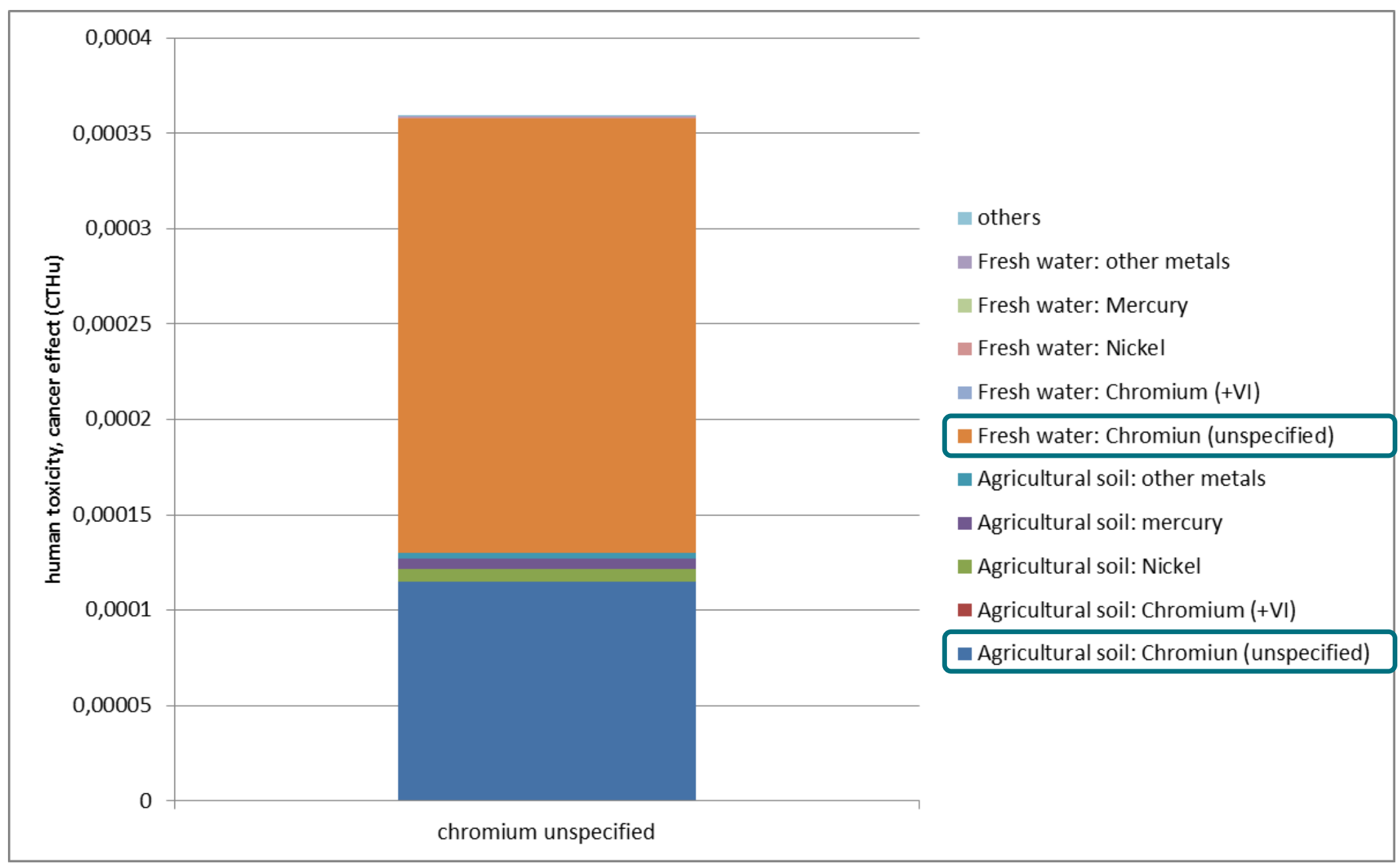




\section{Chromium unspecified?}

- From organic and mineral fertilizer (field emissions)

- C.F. $=$ average of C.F. of $\mathrm{Cr}(+\mathrm{III})$ and $\mathrm{Cr}(+\mathrm{VI})$

- $\operatorname{Cr}($ III): harmless

- $\mathrm{Cr}(\mathrm{VI})$ : very toxic

- Problem: in fertilizer only TOTAL Cr is dosed

- no speciation: too expensive 


\section{Chromium unspecified?}

- Could we predict Cr speciation?

- $\operatorname{Cr}(\mathrm{VI})$ is extremely reactive

- Organic compounds: $\mathrm{Cr}(\mathrm{VI})$ react to $\mathrm{Cr}$ (III)

- Mineral fertilizer: $\mathrm{Cr}$ comes from natural rock

- in the natural environment: only $\mathrm{Cr}$ (III)

$\rightarrow$ Most of the $\mathrm{Cr}=\mathrm{Cr}$ (III)

$\rightarrow$ Confirmation in literature 
- Test with $95 \%$ of $\mathrm{Cr}$ as $\mathrm{Cr}$ (III) and the rest as $\mathrm{Cr}(\mathrm{VI})$

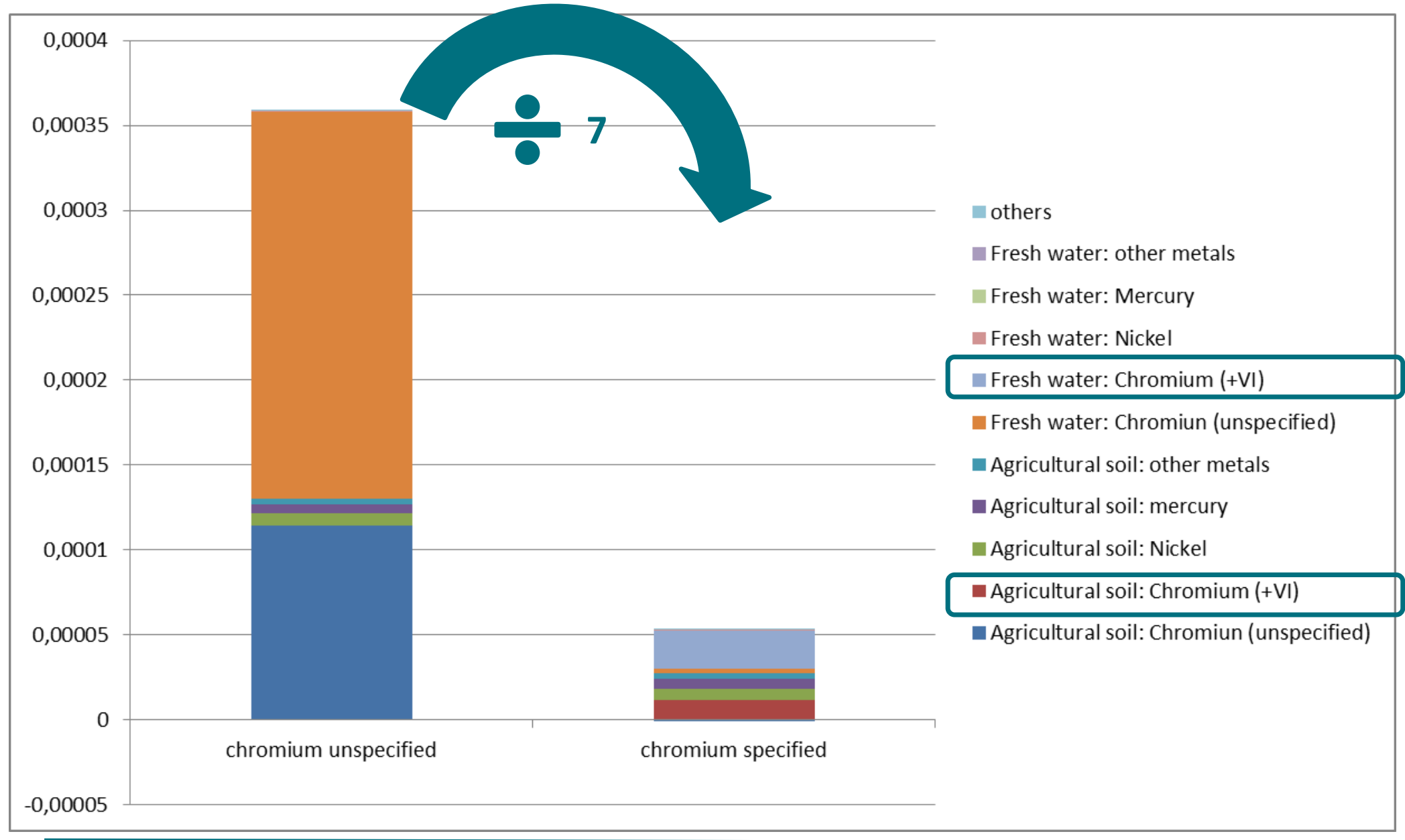




\section{Human toxicity, Cancer effect}

- Pesticide contribution negligible

- $2.2 \mathrm{~kg}$ of pesticides applied by hectare: only $1.2 \mathrm{~kg}$ is characterized

- Most of them have only C.F. in human toxicity non-cancer effect

- Glyphosate: only a C.F. in human toxicity, non-cancer effect

- classified as probably carcinogenic by the World Health Organization

- C.F. of the pesticides is small compared to the C.F. of metals 


\section{Human toxicity, Cancer effect}

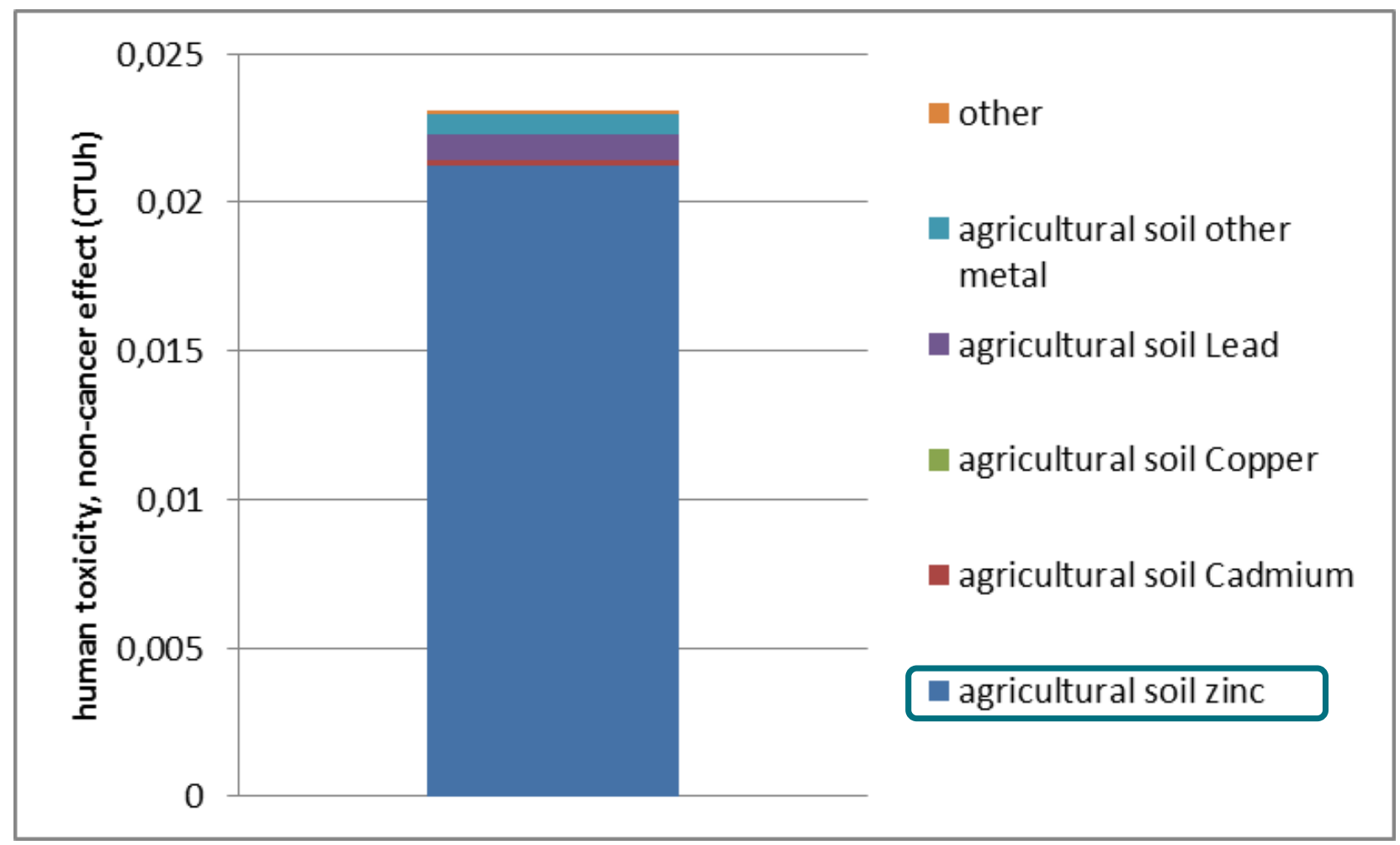


- From organic fertilizers (pig manure)

- Zinc: abundant/important trace element in the human body:

- useful for growth, bone and brain development, etc.

- European Commission recommendation: $7-10 \mathrm{mg} /$ person/day

- Human bodies are able to eliminate the zinc to maintain a constant level

- Only the exposure to high doses can have toxic effects:

- interferes with the uptake of copper 
- USEtox:

- $\mathrm{CF}=$ the effects [cases $\left./ \mathrm{kg}_{\text {intake }}\right]^{*}$ the intake fraction $\left[\mathrm{kg}_{\text {intake }} / \mathrm{kg}_{\text {emmitted }}\right]$

- Zinc

- effect factor: small in comparison to other metals

- intake fraction: high

$\rightarrow$ a substance that is relatively harmless obtains a large impact in toxicity.

- But is the exposition so high that we are in a toxic case?

- And pesticides? 


\section{Human toxicity, non-cancer effect}

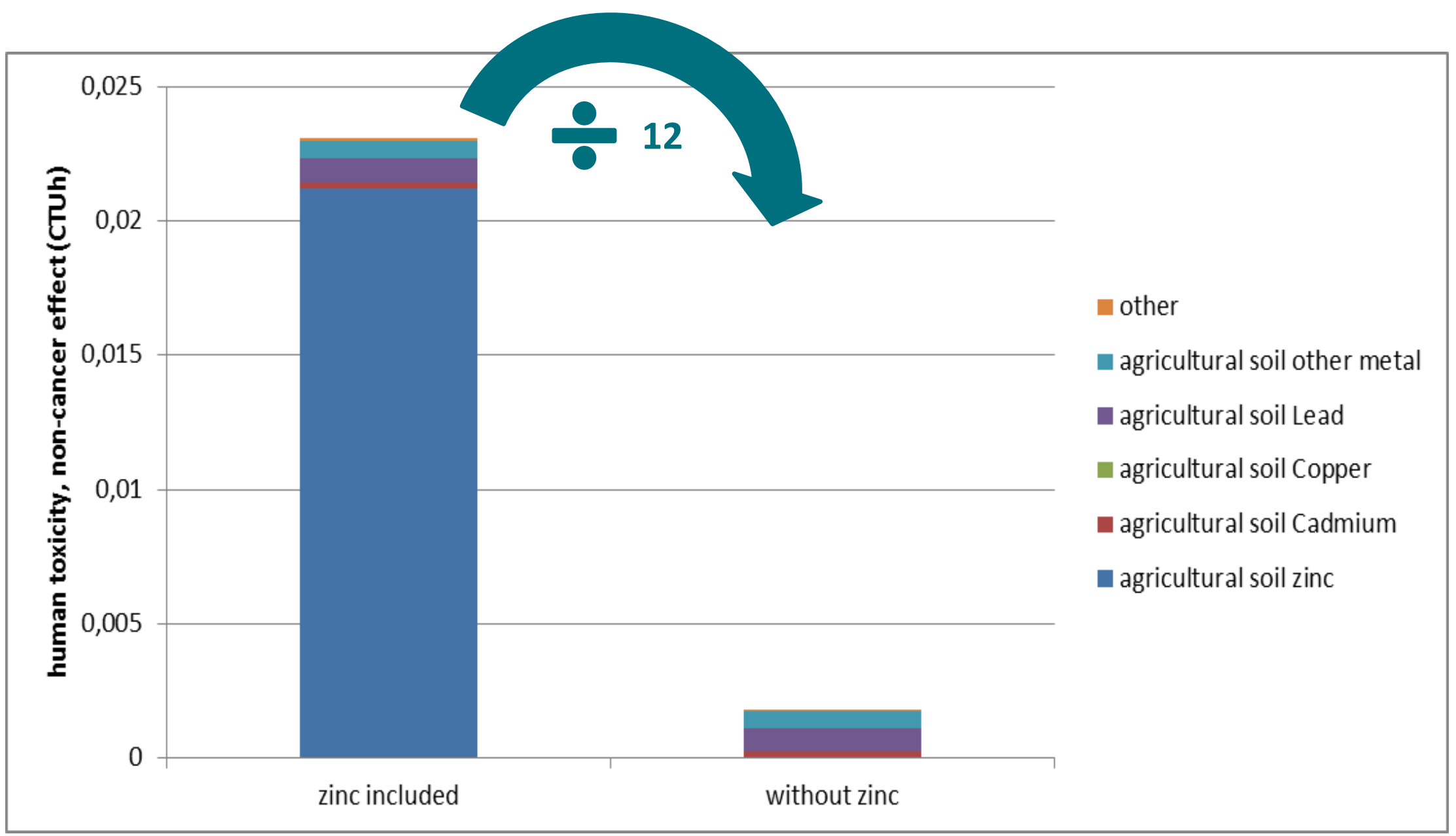




\section{Conclusion}

- Small contribution of pesticides

- no difference between organic and traditional agriculture if only the farming is considered

- Importance of the speciation of some metals!

- Detailed analyze is mandatory! Especially for toxicity categories

- Some C.F. are difficult to understand... 


\section{Conclusion}

\section{Human toxicity, cancer effect}

- Why C.F. of pesticides so small?

- Why C.F. of $\mathrm{Cr}$ unspecified is the average of $\mathrm{Cr}(\mathrm{III})$ and $\mathrm{Cr}(\mathrm{VI})$ even if $\mathrm{Cr}(\mathrm{VI})$ is so rare in the environment?

Human toxicity, non-cancer effect

- How can we know that zinc is in so large amount that it is toxic?

- Overestimation?

- Why C.F. of pesticides so small? 
- Florence (CRA-W) for the data

- Eric (Knauf Insulation) for the explanation (and patience) about metals toxicity

- Martin Baitz and Morten Kokborg (ThinkStep) for the detailed explanation about GaBi processes / flow / hypothesis and discussion

- All the LCA-team of ULiège (including past members!)

- You $:$ for your attention 